University of Nebraska - Lincoln

DigitalCommons@University of Nebraska - Lincoln

7-2009

Juveniles' Knowledge of the Court Process: Results from Instruction from an Electronic Source

Christine Driver

Eve M. Brank

Follow this and additional works at: https://digitalcommons.unl.edu/psychfacpub

Part of the Juvenile Law Commons, and the Psychology Commons

This Article is brought to you for free and open access by the Psychology, Department of at

DigitalCommons@University of Nebraska - Lincoln. It has been accepted for inclusion in Faculty Publications, Department of Psychology by an authorized administrator of DigitalCommons@University of Nebraska - Lincoln. 


\title{
Juveniles' Knowledge of the Court Process: Results from Instruction from an Electronic Source
}

\author{
Christine Driver and Eve M. Brank \\ Law-Psychology Program, Department of Psychology, University of Nebraska-Lincoln, Lincoln, \\ Nebraska, USA \\ Corresponding author - Eve M. Brank, JD, PhD, University of Nebraska-Lincoln, Department of Psychology, Law- \\ Psychology Program, PO Box 880308, Lincoln, NE 68588-3328, USA, email ebrank2@unl.edu
}

\begin{abstract}
Our study first determined what juveniles know about the juvenile court process. Second, it evaluated a DVD designed to be a systematic and simple way to improve this knowledge. A pre- and posttest design was used with two pilot samples and two samples from the population of interest. A sample from a juvenile detention center $(n=118)$ was the focus of this study. Initial knowledge of the court process was quite low for the detention sample (pretest $M=64.0 \%, \mathrm{SD}=14.2 \%$ ). All samples experienced a significant improvement of knowledge after watching the DVD. Youth in the detention sample had a mean improvement from pretest to posttest of $6.4 \%(\mathrm{SD}=11.9 \%)$, with mean scores at posttest being $70.3 \%(\mathrm{SD}=17.4 \%)$. Respondents varied in their performance on different question topics, scoring the lowest on questions related to what happens at juvenile court hearings. The social and demographic variables of age, race, gender, grades in school, number of previous arrests, and the number of times the respondent had been to court were evaluated through regression analysis. Age and race were found to be significantly related to pretest scores, and race was significantly related to improvement scores.
\end{abstract}

Knowledge of the court process is integral in juveniles' ability to participate in the factfinding for their cases, yet research demonstrates that juveniles lack a complete understanding of the processes employed by the juvenile court (Cooper, 1997; Grisso, 1981; O'Connor, 1990; Peterson-Badali \& Abramovitch, 1992; Peterson-Badali, Abramovitch, \& Duda, 1997; Redlich, Silverman, \& Steiner, 2003; Savitsky \& Karras, 1984; Warren-Leubecker, 
Tate, Hinton, \& Ozbek, 1989), and this lack of knowledge is often overlooked when a juvenile is brought to court ( $\mathrm{O}^{\prime}$ Connor, 1990). The rehabilitative purpose of the juvenile court is put into jeopardy when the juvenile does not understand the court process because the juveniles become passive parties in their cases and are unable to understand the impact the proceedings will have on their lives. The current study addresses juveniles' understanding of the system and whether their knowledge can be improved through an instructional DVD introducing them to basic vocabulary and concepts.

The literature reviewed for the current research is divided into two main sections. First, we discuss the fact that juvenile comprehension of the elements of the juvenile system seem low, despite changes in the juvenile system that make comprehension essential. Second, we shall examine education research that focuses on new vocabulary acquisition as models for examining the use of a DVD to teach juveniles what they need to know about the juvenile justice system.

\section{Juvenile Knowledge of the System}

Research has consistently demonstrated that juveniles lack understanding of basic legal concepts. Juveniles, especially young juveniles, have a difficult time understanding Miranda warnings and the role of defense attorneys (Grisso, 1981). Although understanding of legal terms does seem to increase with age (Saywitz, Jaenicke, \& Camparo, 1990; WarrenLeubecker et al., 1989), juveniles struggle with procedural and technical terms (Smith, 1985), especially when asked to conceptualize legal terms (Flin, Stevenson, \& Davies, 1989; Peterson-Badali \& Abramovitch, 1992). In practice, this means that juveniles often do not fully understand the role of their attorneys (Peterson-Badali et al., 1997; Redlich et al., 2003), and they see themselves as passive parties in the court process, even believing they should remain silent throughout (O'Connor \& Sweetapple, 1988). Juveniles' appreciation for the significance of legal circumstances for their defense may be compromised if they do not understand the meaning of their plea of not guilty, that they are innocent until proven guilty, or other rights they possess (Cooper, 1997; Grisso, 1981; Peterson-Badali \& Abramovitch, 1992). Juveniles may also be disadvantaged in their ability to communicate information to counsel if they mistakenly believe the lawyer will not represent them if the lawyer thinks the juvenile is guilty or if they do not understand the attorney-client privilege (Cooper, 1997; Grisso, 1981; O'Connor, 1990; Peterson-Badali \& Abramovitch, 1992; Peterson-Badali et al., 1997; Redlich et al., 2003). Although a juvenile's understanding of the legal process, and the resulting fairness of this process, is compromised if they do not understand these key legal concepts used within the system, research demonstrates that it is happening (Cooper, 1997; Flin et al., 1989; Savitsky \& Karras, 1984; Saywitz et al., 1990; Warren-Leubecker et al., 1989).

Most state juvenile justice codes use the Dusky v. U.S. (1960) adult competency case as a basis for their competency definitions. For instance, in Florida, the state where the current research took place, the statute states that "a child is competent to proceed if the child has sufficient present ability to consult with counsel with a reasonable degree of rational understanding and the child has a rational and factual understanding of the present proceedings." The statute also requires a report addressing the juvenile's capacity on the following 
points: (1) appreciation of the charges or allegations against the child, (2) appreciation of the range and nature of possible penalties that may be imposed in the proceedings against the child, if applicable, (3) understanding of the adversarial nature of the legal process, (4) ability to disclose to counsel facts pertinent to the proceedings at issue, (5) ability to display appropriate courtroom behavior, (6) ability to testify relevantly (Incompetency in Juvenile Delinquency Cases, 2006). Researchers who study competency generally divide the Dusky requirements into two basic concepts, (1) competence to assist counsel and (2) decisional competence (Bonnie, 1992). The criterion of competence to assist counsel examines the ability of the individual to understand the trial process, appreciate the significance of legal circumstances for the defense, and communicate information to counsel. Decisional competence examines their ability to weigh and compare options, including determining the probability of consequences (Bonnie). The current study addresses whether some components of competency can be taught to juveniles in a systematic and efficient way.

\section{Teaching Methods and Rehabilitating Comprehension}

A number of different teaching methods can be employed to more systematically aid juveniles in their understanding of legal vocabulary. These could include using language that is more common to the juvenile's current vocabulary and the use of multimedia sources such as videos and pictures. Analogous to a person learning a second language, juveniles within the juvenile justice system must learn many new terms and concepts and be able to make decisions and communicate with others about those concepts. Second language acquisition research has demonstrated that the use of the learner's native language is especially important in teaching new vocabulary (Lotto \& deGroot, 1998). Combining pictures and videos with text can be even more beneficial (Chun \& Plass, 1996; Duquette \& Painchaud, 1996). Cooper (1997) employed these techniques in her study that focused specifically on increasing juveniles' legal competency through an instructional video presentation of legal concepts. Using a 50-minute instructional videotape, Cooper employed a preand posttest design focusing on juveniles who were experiencing their first institutional placement for delinquency and obtained a competency score below what was needed to be considered competent. The video described the roles of those involved in the trial process, where each of the participants were placed in the courtroom, information regarding different offenses, and instructions on how to contact and assist counsel. A question and answer period followed the presentation to allow the juveniles to obtain clarification on any concepts. The video produced a significant improvement in understanding of proceedings in all age groups, but even with this improvement most juveniles still did not receive scores on a standard competency instrument that indicated competency.

Cooper's (1997) study provided the foundation for the current research. Many of the concepts evaluated for competency determinations by Cooper were modified in the current study to evaluate juvenile knowledge and understanding. In addition, comfort level of the juvenile was also examined based on the findings of Bradshaw, Ross, Bradshaw, Headrick, and Thomas (2005). In their study, potential jurors who were shown a video tape containing key legal information were significantly more knowledgeable than potential 
jurors who were not exposed to the video tape, and this knowledge was positively correlated to juror comfort. As the research has demonstrated, instructional videos can be useful teaching tools for increasing knowledge of the justice system and comfort (Bradshaw et al., 2005; Chun \& Plass, 1996; Cooper, 1997; Duquette \& Painchaud, 1996).

\section{Current Research}

It is clear that juveniles lack complete understanding of the juvenile justice system; however, education research and other instructional studies demonstrate that there may be simple ways to improve a juvenile's level of understanding and comfort within the system. The current research tests whether an instructional video (Couch, 2005-hereafter referred to as the DVD) portraying juvenile system related information is able to increase juvenile understanding of the process. We also compare social and demographic factors (e.g. age, prior school performance, and prior experience in the justice system) as they relate to knowledge improvement. Additionally, we examine whether certain types of knowledge are more difficult for the juveniles to master.

\section{Method}

\section{Participants}

The current study took place in four phases, two pilot phases and two phases involving participants of interest. The response rates for each group were calculated based on the number of surveys and consent/assent forms or parental consent forms distributed compared with those returned. Response rates are approximate for some of the samples because consent/assent forms were distributed to entire classrooms and to minimize feelings of coercion no formal count of students who were present, but did not take a consent form, was recorded. Those participants who were present for only one day of the study and completed either the pre- or posttest are counted as a nonresponse for the purposes of the current research.

\section{College Pilot Sample}

The sample for the college phase of this study consisted of 55 undergraduate students (16 males and 39 females) from two undergraduate Juvenile Law classes at the University of Florida. The response rate was about $55 \%$ for this sample. Twenty 20 participants were not included in this sample because they were not present for both days of the study. Two classes were sampled with approximately 50 students registered for each class. The study took place at the beginning of the semester when the students had not yet received substantial training on juvenile law issues.

Juvenile Pilot Sample

The sample for the juvenile pilot phase of the current study included 54 students from the University of Florida laboratory middle and high school. The sample consisted of both male $(n=19)$ and female $(n=35)$ students between the ages of 11 and $17(M=14.44, \mathrm{SD}=$ 1.76). Participants were included in the study only if both parental consent and participant 
consent were obtained. The response rate was about $45 \%$ for this sample. Nine participants were not included in this sample because they were not present for both days of the study. Four classes were sampled with approximately 30 students per class. A failure to return the parental consent form was the major reason for nonparticipation.

Juveniles in an Alternative Public School Sample

Forty-seven juveniles (36 males and 11 females, age: $M=15.15, \mathrm{SD}=1.21$ ) attending an alternative public middle and high school (the school is primarily for students with previous histories of disruptive behaviors) were sampled. Passive parental consent was used for participants in this sample; parents signed and returned the consent form if they did not want their child to participate. Active consent was obtained from the juveniles. The response rate was $56 \%$ for this sample. Thirty-one participants were excluded because they were not present for both days of the study, and six chose not to participate.

\section{Detention Sample}

The detention sample consisted of 118 juveniles (110 males and 8 females) who were being held at a juvenile detention center $(M=15.55$ years old, $\mathrm{SD}=1.37)$. The approximate response rate was $71 \%$ for this sample. There were 167 juveniles sampled, and of these, 48 participants were not included because they left the detention center before day 2 of the study and 13 chose not to participate. Data collection in the detention center took place over the course of 13 months.

\section{Materials}

\section{The DVD}

A DVD was jointly developed by the Office of Court Improvement and the Steering Committee on Families and Children in the Court for the State of Florida to improve juveniles' comprehension of trial-related information. The DVD was developed to address some areas where juveniles show deficits in understanding and commonly hold misconceptions concerning legal terms and concepts. In the past, pamphlets were provided to the juveniles explaining some of this trial-related information. The DVD is intended to have a wider and more effective impact because it will be able to reach those juveniles who are not strong readers and because the information is presented in a more interactive way. This DVD was developed for the target audience of juveniles in the juvenile justice system and their parents. The goal was to show it in detention centers, courthouses, probation offices, and assessment centers throughout Florida. At the time of the current study, the DVD had not yet been implemented in the detention system in the county of the current study.

\section{Knowledge Test}

The current study's questionnaire is based on previous research, information contained in the DVD, and questions suggested from detention center staff. These questions are not based on any formal competency screening measure, but rather are measures of knowledge of the court process that relate to competency. The final questionnaire consists of 40 
total questions, 11 of which assess social and demographic data. Question content and format will be examined in the following sections.

\section{Role of the Lawyer and Attorney Client Confidentiality (LAWYER)}

Five of the questions included on the questionnaire relate to the lawyer's role in the courtroom and attorney-client privilege (Cooper, 1997; Flin et al., 1989; Grisso, 1981; PetersonBadali \& Abramovitch, 1992; Saywitz et al., 1990; Warren-Leubecker et al., 1989). For example, the participants were asked "Who in the courtroom would you tell something important about your case if you wanted it to be kept just between you and that person?" Possible answer choices were "the judge," "your lawyer," "the social worker," and "the state attorney," with "your lawyer" being the correct answer.

\section{Roles of Key Players in the Courtroom (KEY PLAYERS)}

The roles of other key players in the courtroom are addressed with five additional questions, such as "Who makes the decision of whether you are guilty or not at your trial?" Possible answer choices are "your lawyer," "the judge," "the jury," and "the police officer," with "the judge" being the correct answer. Other questions focus on the state attorney, probation officers, bailiff, and judge.

\section{Nature and Consequences of the Charges (NATURE)}

Three questions are included on juveniles' understanding of the nature and consequences of the charges. For instance, one asks "Todd, who is 15, was arrested and is being sentenced for a crime that he committed. What are some of the things he could be sentenced to do?" Possible answers were "community service - volunteer in the community," "go to school," "attend a day treatment program," "get counseling," and "write an apology letter." All five answer choices here were correct, and the question was scored as five possible points.

\section{Juvenile Court Hearings (HEARINGS)}

The juveniles' knowledge of the differences between the types of hearing is tested by six questions. One of the questions asked "Kyle, who is 14, is caught breaking car windows by the police. The police take him and put him in a detention center. When will Kyle go to court for the first time?" The answer choices included "the arraignment hearing," "the detention hearing," "the disposition hearing," and "the adjudication hearing," with the correct answer being "the detention hearing."

\section{Pleas (PLEAS)}

The one question on pleas asks juveniles "Which of the following pleas can you enter? Check all that apply." The answer choices were "not guilty," "innocent," "no contest," and "guilty," and the only incorrect answer was "innocent."

\section{Court Behavior (BEHAVIOR)}

Two questions examine juveniles' perceptions of proper behavior regarding their case. One of these asks "If you were living at home and had a court date scheduled, what would you do if your parents could not take you to court at the time you are supposed to be 
there?" Answer choices include "find another ride," "skip your court date," and "call the courthouse and ask to be excused," with "find another ride" being the correct answer.

Application (APPLICATION) versus Non-Application (NONAPPLICATION) Questions

Five of the questions that were included in the questionnaire sections described above required the respondent to apply information presented in the DVD in order to answer the question. For instance, one asks "Nick, who is 17 , is in court and does not understand what the judge is saying. What should he do?" The answer choices included "keep quiet to show the judge respect," "let the judge know that he doesn't understand" (correct), and "ask someone what the judge meant after the hearing." Fourteen questions were more definitional in nature and did not require the juveniles to apply their learned knowledge to a described scenario.

\section{Information Not Included in the DVD (NON-DVD)}

Three questions were included that addressed information that was not in the DVD. One question addressed innocence and guilt and the other two were included based on suggestions from the detention center staff that they had found juveniles frequently asked while detained. These questions served two purposes: to evaluate what the juveniles knew about those topics and as a control to ensure knowledge improvement at posttest comes from the DVD rather than an outside source. If knowledge increased on these questions, the effect would not be from the DVD but rather testing effects or some outside source.

\section{Sureness of Correct Answer Choices}

One question was included to test the participants' perceived certainty of their answers on the questionnaire. This was based on the research that found juror comfort was positively related to juror knowledge and both increased when shown a video intended to increase their knowledge (Bradshaw et al., 2005).

Pre- versus Posttest Questions

Three questions varied between the pretest and posttest versions. These questions evaluated whether participants came in with or received any information that could affect their scores. One such question was "Have you spoken with anyone about the video you watched on the first day we were here?" Participants chose either yes or no.

\section{Question Order}

Question order was randomized for the pilot samples, but we determined that there was no order effect, so this was not continued for the alternative school and detention samples.

\section{Grading}

The grading of the questionnaire was based on the 19 DVD knowledge questions that the respondent answered correctly. The three open-ended questions were excluded from this knowledge score and evaluated separately. Missing responses were treated as incorrect, just as they would have been had this been any type of academic examination. Because some questions had multiple correct answers, the highest raw score a participant could 
obtain on the questionnaire was a 44 . The total possible raw score for each section described is as follows: LAWYER-10, KEY PLAYERS-16, NATURE-6, HEARINGS-6, PLEAS-4, BEHAVIOR-2, NON-DVD-3, APPLICATION-9, and NONAPPLICATION-35. Throughout the remainder of this paper scores will be presented as percentages in most cases. For ease of interpretation, scores will also be compared using a common college letter grading scale.

\section{Design}

A pre- and posttest design was employed to evaluate whether the information presented in the DVD aids in increasing understanding of key terms and concepts related to the juvenile court process. Scripts were used that included general information on the study, what we were asking them to do, and information concerning their voluntary participation and confidentiality of information. For all samples but the college sample, the questionnaires were read out loud to the survey participants. Corresponding pictures were used for each question to keep the participants following along and to ensure that even those who could not read could participate in the study.

Immediately after the participants had completed the pretest questionnaires, they watched the DVD; two days later they completed the posttest. A two-day delay was employed because the relevant state statute states that a "child may not be held in secure detention under this subparagraph for more than 48 hours unless ordered by the court" (Use of Detention Statute, 2006). The two-day delay reflects the maximum amount of time that a juvenile may wait between first arriving in detention and appearing for their first hearing. Therefore, if the juveniles are shown the DVD at intake, it could be up to two days before they appear in court.

\section{Results}

\section{College Pilot Sample}

The college pilot sample served as our expert group in this study to ensure that the knowledge-based test was not too difficult and to serve as a comparison group for other samples. For this sample the mean pretest score was an $83.1 \%$. This indicates that the initial knowledge level of the "expert" sample is in the B range. A one-tailed paired samples $t$-test was used to test whether there was a significant difference between pretest and posttest scores for this sample. A significant difference was present between mean pretest $(83.1 \%$, $\mathrm{SD}=6.9 \%)$ and mean posttest $(92.0 \%, \mathrm{SD}=5.4 \%)$ score $(t(54)=-9.71, p<.001)$. The mean improvement percentage was $8.1 \%(\mathrm{SD}=6.6 \%)$.

\section{Juvenile Pilot Sample}

The sample of juveniles in a university laboratory middle and high school served two specific purposes. One was to ensure that the questionnaire was comprehensible to juveniles that were the same ages as the population of interest. The second was to assess how a group of juveniles without justice system involvement would score on the questionnaires, therefore providing a comparison group to the juveniles in detention. The mean pretest 
score for this sample was $67.8 \%$, which is in the $\mathrm{D}$ range. A one-tailed paired samples $t$-test was used to test whether there was a significant difference between pretest and posttest scores for this sample. A significant difference was present between mean pretest $(67.8 \%$, $\mathrm{SD}=7.5 \%)$ and mean posttest $(79.7 \%, \mathrm{SD}=8.0 \%)$ score $(t(53)=-13.01, p<.001)$. The mean improvement score was $11.9 \%(\mathrm{SD}=6.9 \%)$.

\section{Juveniles in an Alternative Public School Sample}

The sample of juveniles in an alternative public school was included because most had experienced some contact with the juvenile justice system and provided for a test of juveniles with some juvenile court experience, but this information was not fresh in their minds because they were not currently in detention. Mean pretest scores for this sample were $63.1 \%$, scoring in the D range. A one-tailed paired samples $t$-test was used to test whether there was a significant difference between pretest and posttest scores for this sample. A significant difference was present between mean pretest $(63.1 \%, \mathrm{SD}=10.7 \%)$ and mean posttest $(68.1 \%, \mathrm{SD}=15.1 \%)$ score $(t(46)=-2.24, p<.05)$. The mean improvement score was $5.0 \%(\mathrm{SD}=15.3 \%)$.

\section{Detention Sample}

The detention sample's pretest scores were examined to establish their base level of juvenile court knowledge. Juveniles in this sample had a mean pretest score of $64.0 \%$. This score was in the D range. A one-tailed paired samples $t$-test was used to test whether there was a significant difference between pretest and posttest scores for the detention sample. A significant difference was present between mean pretest $(64.0 \%, \mathrm{SD}=14.2 \%)$ and mean posttest $(70.3 \%, \mathrm{SD}=17.4 \%)$ score $(t(117)=-5.73, p<.001)$ for the detention sample. The mean improvement score was $6.4 \%(\mathrm{SD}=11.9 \%)$.

To confirm that the improvement between pre- and posttest was based on the information gleaned from the video and not just on testing effects, we evaluated whether there were significant improvements from pre- to posttest on the questions that were not included in the video (NON-DVD). The three questions that were included on the questionnaire but not on the DVD were grouped together. A two-tailed paired samples $t$-test was conducted to determine whether there was a significant change from mean pretest score $(46.3 \%, \mathrm{SD}=$ $26.9 \%)$ to mean posttest score $(48.9 \%, \mathrm{SD}=23.7 \%)$. The change from pre- to posttest was not found to be significant $(t(117)=-1.08, p=.525)$. This means that the participants' knowledge improved on the topics covered in the DVD but not on the material not included in the DVD.

Social and demographic variables were next examined for this sample to determine whether age, grades, or prior experience had any influence on pretest or improvement scores while controlling for race and gender. The detention sample $(n=118)$ had an age range of 11-18 years old. Their average grades in school ranged from mostly A's (9) to mostly F's $(1)(M=5.69 ; \mathrm{SD}=1.93)$. There were 55 participants who identified themselves as White/Other and 62 identified themselves as African American. There were 112 participants who indicated they knew others with previous criminal or juvenile justice experience. The number of previous arrests indicated by participants ranged from 0 to 5 or more 
$(M=1.87 ; \mathrm{SD}=1.76)$. The number of previous times in court ranged from 0 to 5 or more $(M=2.92 ; \mathrm{SD}=1.84)$.

Two linear regression analyses were conducted, one for each dependent variable, pretest scores and improvement scores. Missing cases were excluded pairwise for this analysis. The independent variables included in each model were age, race, gender, grades, number of previous arrests, and number of times the respondent had been to court. The number of times the respondent had been to court was an additive combination of the following two questions: (1) How many times have you been to court for cases you were involved in? (2) How many times have you been to a courtroom for a case you were not directly involved in? The variable of whether the respondent knew anyone who had been arrested as either juvenile or an adult was a combination of two questions, one asking if they knew anyone arrested as a juvenile, and one asking if they knew anyone arrested as an adult; answers were coded as yes if they answered yes to either of these questions. This variable was not included in this analysis because only five juveniles in this sample said that they did not know anyone who had previously been arrested. Regression analysis showed that the model significantly predicted knowledge at pretest $(F(6,67)=2.63, p=$ $.024, R^{2}=.191$ and $R^{2}$ adj $=-.118$ ). Table 1 includes the unstandardized regression coefficients $(B)$, intercept, and standardized regression coefficients $(\beta)$ for each variable. Age, $t(114)=$ $2.50, p<.05$, significantly predicted knowledge at pretest, with older juveniles scoring higher. Race, $t(117)=-2.06, p<.05$, also significantly predicted knowledge at pretest, with those identifying as White/Other scoring higher. The second model did not significantly predict knowledge improvement, $F(6,67)=1.69, p=.138, R^{2}=.131$ and $R^{2}$ adj $=.053$. Table 1 includes the unstandardized regression coefficients $(B)$, intercept, and standardized regression coefficients $(\beta)$ for each variable. Race, $t(117)=2.81, p<.005$, significantly predicted knowledge improvement, with those who identified as African American showing more improvement than those who identified as White/Other. No other independent variables were significant predictors for knowledge improvement. 
DRIVER AND BRANK, BEHAVIORAL SCIENCES AND THE LAW 27 (2009)

Table 1. Regression: Social-demographic variables' relationship to pretest and improvement scores

\begin{tabular}{|c|c|c|c|c|c|c|c|}
\hline & M & SD & $B$ & $\beta$ & $t$ & $\mathrm{df}$ & $p$ \\
\hline \multicolumn{8}{|l|}{ Pretest } \\
\hline Age $^{*}$ & 15.55 & 1.37 & 0.030 & 0.289 & 2.503 & 114 & .011 \\
\hline Grades ( $1=$ mostly F's $-9=$ mostly A's $)$ & 5.69 & 1.93 & -0.002 & -0.025 & -0.227 & 107 & .821 \\
\hline Gender ( 1 = male, 2 = female $)$ & 1.07 & 0.25 & 0.034 & 0.060 & 0.536 & 117 & .594 \\
\hline $\begin{array}{l}\text { Race }(1=\text { Other, } 2=\text { African } \\
\text { American })^{*}\end{array}$ & 1.53 & 0.50 & -0.073 & -0.257 & -2.308 & 117 & .024 \\
\hline Number of previous arrests & 1.87 & 1.76 & -0.012 & -0.153 & -1.157 & 85 & .251 \\
\hline Number of times previously in court & 4.51 & 5.26 & 0.010 & 0.121 & 0.922 & 92 & .360 \\
\hline \multicolumn{8}{|l|}{ Improvement } \\
\hline Age & 15.55 & 1.37 & 0.017 & 0.193 & 1.680 & 114 & .098 \\
\hline Grades ( $1=$ mostly F's $-9=$ mostly A's $)$ & 5.69 & 1.93 & -0.006 & -0.091 & -0.788 & 107 & .433 \\
\hline Gender $(1=$ male, 2 = female $)$ & 1.07 & 0.25 & 0.036 & 0.076 & 0.655 & 117 & .515 \\
\hline $\begin{array}{l}\text { Race }(1=\text { Other, } 2=\text { African } \\
\text { American })^{* *}\end{array}$ & 1.53 & 0.50 & 0.077 & 0.322 & 2.790 & 117 & .007 \\
\hline Number of previous arrests & 1.87 & 1.76 & 0.002 & 0.030 & 0.217 & 85 & .829 \\
\hline Number of times previously in court & 4.51 & 5.26 & -0.006 & -0.098 & -0.718 & 92 & .475 \\
\hline
\end{tabular}

*Significant independent predictor of pretest scores at $p<.05$.

**Significant independent predictor of pretest scores at $p<.01$.

Mean scores on pre- and posttests for each of the sections were next evaluated. Respondents scored highest in the LAWYER section (pretest $M=75.9 \%$ correct, $\mathrm{SD}=19.7 \%$, posttest $M=77.2 \%$ correct, $\mathrm{SD}=21.8 \%$ ). While this was the easiest section for respondents overall, whether a lawyer represented them whether they were guilty or not proved to be more difficult. At pretest $70.3 \%$ of respondents thought that one of the jobs of the lawyer was to represent a juvenile in the trial if they were not guilty; however, only $45.8 \%$ of respondents thought that the lawyer represented a juvenile in court if he or she was guilty. This demonstrates that about a quarter of those sampled thought the lawyer's role was dependent on whether a juvenile was guilty. There was some improvement at posttest with $53.4 \%$ indicating one's lawyer would represent them if guilty and $71.2 \%$ if not guilty. Respondents had the most difficulty with the HEARINGS section for both the pretest $(27.7 \%$ correct, SD $=22.6 \%)$ and the posttest $(29.1 \%$ correct, $\mathrm{SD}=19.6 \%)$. These and other comparisons can be seen in Table 2. 
Table 2. Mean percentage scores by section topic and type for detention sample

\begin{tabular}{|c|c|c|c|c|c|c|c|}
\hline \multirow[t]{2}{*}{ Section } & \multicolumn{2}{|c|}{ Pretest } & \multicolumn{2}{|c|}{ Posttest } & \multirow[b]{2}{*}{$t$} & \multirow[b]{2}{*}{$\mathrm{df}$} & \multirow[b]{2}{*}{$p$} \\
\hline & $M$ & SD & $M$ & SD & & & \\
\hline Total $^{* * * *}$ & $64.0 \%$ & $14.2 \%$ & $70.3 \%$ & $17.4 \%$ & -5.732 & 117 & .000 \\
\hline NON-DVD & $46.3 \%$ & $26.9 \%$ & $48.9 \%$ & $23.7 \%$ & -1.084 & 117 & .280 \\
\hline LAWYER & $75.9 \%$ & $19.7 \%$ & $77.2 \%$ & $21.8 \%$ & -0.673 & 117 & .503 \\
\hline KEY PLAYERS**** & $69.1 \%$ & $16.7 \%$ & $77.0 \%$ & $20.0 \%$ & -5.153 & 117 & .000 \\
\hline NATURE & $68.8 \%$ & $24.0 \%$ & $78.5 \%$ & $26.0 \%$ & -4.646 & 117 & .000 \\
\hline HEARINGS & $27.7 \%$ & $22.6 \%$ & $29.1 \%$ & $19.6 \%$ & -0.590 & 117 & .557 \\
\hline PLEAS $^{* * * *}$ & $64.2 \%$ & $29.9 \%$ & $76.1 \%$ & $29.6 \%$ & -5.283 & 117 & .000 \\
\hline BEHAVIOR $^{* * * *}$ & $58.1 \%$ & $34.0 \%$ & $69.9 \%$ & $35.9 \%$ & -3.559 & 117 & .001 \\
\hline APPLICATION ${ }^{* * * *}$ & $64.8 \%$ & $21.2 \%$ & $71.8 \%$ & $24.6 \%$ & -3.772 & 117 & .000 \\
\hline NON-APPLICATION ${ }^{* * * *}$ & $63.8 \%$ & $14.2 \%$ & $69.9 \%$ & $16.8 \%$ & -5.077 & 117 & .000 \\
\hline
\end{tabular}

${ }^{* * * *}$ Difference between pre- and posttest scores significant at $p<.001$.

Next, sure scores were compared using a one-tailed paired samples $t$-test. Sure scores were measured on a four-point scale with $1=$ not sure and $4=$ very sure as a way to determine how confident the juveniles were with their answers. A significant increase between mean sure scores at pretest $(M=2.90, \mathrm{SD}=0.80)$ and at posttest $(M=3.13, \mathrm{SD}=0.73)$ was found $(t(112)=-3.66, p<.001)$. A significant correlation was found $(r=0.284, p=.002)$, with those who were more sure showing more improvement.

Data from the open-ended questions was next examined. The questions along with the percentage of juveniles choosing each question are included in Table 3. The largest percentage for both pretest $(63.6 \%)$ and posttest $(70.3 \%)$ wrote in their lawyer as the person they would most likely tell important information about their case.

Table 3. Open ended questions and responses

\begin{tabular}{lrr}
\hline & Pretest & Posttest \\
\hline If you are found guilty at your trial, what is the longest your punishment could last? & & \\
Days (less than 1 month) & $17.8 \%$ & $21.2 \%$ \\
Months (less than 1 year) & $7.6 \%$ & $8.5 \%$ \\
1 year & $1.7 \%$ & $3.4 \%$ \\
2-4 years & $4.2 \%$ & $1.7 \%$ \\
5-9 years & $2.5 \%$ & $3.4 \%$ \\
Over 10 years (less than life) & $5.9 \%$ & $5.9 \%$ \\
Life & $14.4 \%$ & $17.8 \%$ \\
Until age 18 & $3.4 \%$ & $2.5 \%$ \\
Until age 21 & $1.7 \%$ & $2.5 \%$ \\
Depends & $0 \%$ & $1.7 \%$ \\
Missing & $40.7 \%$ & $31.4 \%$
\end{tabular}


DRIVER AND BRANK, BEHAVIORAL SCIENCES AND THE LAW 27 (2009)

Table 3. Continued

\begin{tabular}{|c|c|c|}
\hline & Pretest & Posttest \\
\hline \multicolumn{3}{|c|}{ If you were to tell someone important information about your case, who would be the best person to tell? } \\
\hline Lawyer/attorney & $63.6 \%$ & $70.3 \%$ \\
\hline Parents & $17.8 \%$ & $15.3 \%$ \\
\hline Adult (other than attorney/parents/police) & $2.5 \%$ & $0.8 \%$ \\
\hline Police & $0.8 \%$ & $0 \%$ \\
\hline Friends & $0.8 \%$ & $0.8 \%$ \\
\hline Judge & $1.7 \%$ & $0.8 \%$ \\
\hline Social worker & $1.7 \%$ & $1.7 \%$ \\
\hline Probation officer & $8.5 \%$ & $8.5 \%$ \\
\hline State attorney & $0 \%$ & $0.8 \%$ \\
\hline Missing & $5.1 \%$ & $4.2 \%$ \\
\hline \multicolumn{3}{|c|}{ If you were to tell someone important information about your case, why would you tell the person in the previous question } \\
\hline Client confidentiality & $5.1 \%$ & $8.5 \%$ \\
\hline Best person to help & $44.1 \%$ & $39.0 \%$ \\
\hline Works for you & $15.3 \%$ & $18.6 \%$ \\
\hline Other & $14.4 \%$ & $5.1 \%$ \\
\hline Missing & $23.7 \%$ & $32.2 \%$ \\
\hline \multicolumn{3}{|c|}{ Who would you be least likely to tell important information about your case? } \\
\hline Prosecutor/state attorney & $29.7 \%$ & $36.4 \%$ \\
\hline Judge & $15.3 \%$ & $18.6 \%$ \\
\hline Probation officer & $5.9 \%$ & $6.8 \%$ \\
\hline Social worker & $1.7 \%$ & $1.7 \%$ \\
\hline Police & $11.9 \%$ & $8.5 \%$ \\
\hline Jury & $0 \%$ & $1.7 \%$ \\
\hline Friends & $5.1 \%$ & $4.2 \%$ \\
\hline Parents & $3.4 \%$ & $7.6 \%$ \\
\hline My lawyer/attorney & $0 \%$ & $0.8 \%$ \\
\hline Other & $7.6 \%$ & $10.2 \%$ \\
\hline Missing & $20.3 \%$ & $15.3 \%$ \\
\hline \multicolumn{3}{|c|}{ Why is the person from the previous question who you would least likely tell? } \\
\hline Information could be used against me & $14.4 \%$ & $19.5 \%$ \\
\hline Could determine guilt or innocence & $9.3 \%$ & $17.8 \%$ \\
\hline Could get into trouble & $7.6 \%$ & $12.7 \%$ \\
\hline Other & $22.9 \%$ & $4.2 \%$ \\
\hline Missing & $44.1 \%$ & $38.1 \%$ \\
\hline
\end{tabular}




\section{Discussion}

This study was undertaken for two purposes. The first was to determine what juveniles currently understand about the juvenile court system. Juveniles in detention as well as those in the pilot and the alternative school sample scored in the D range on the pretest, compared with the expert sample (college pilot), which scored in the B range on a ten-point academic scale. This demonstrates that the juvenile samples' current knowledge of the juvenile court system was fairly low prior to watching the DVD.

The second purpose of this study was to evaluate whether the DVD achieved its intended purpose of presenting information about the juvenile court process in an understandable way that could increase the viewer's knowledge of the juvenile court system. A significant increase from pre- to posttest was found for all samples. Even though scores did increase significantly after watching the DVD, there is still room for additional improvements. These findings are consistent with those from Cooper's (1997) study detailed above. In Cooper's study, posttest scores for more than half of the sample still did not achieve competency, showing that there were still considerable lapses in understanding after watching the video. Though the current study is an evaluation of knowledge rather than competency, the findings are very similar. Although there is still room for improvement, the current findings indicate that there is a simple and systematic way to increase juvenile knowledge of the court process. Possibilities for further knowledge improvement include allowing juveniles to ask questions after watching the DVD.

Some other noteworthy findings included that some juveniles thought a lawyer represented a juvenile in court only if they were not guilty. Half of the detention sample thought the lawyer did not represent a juvenile in court if that juvenile was guilty. This finding that juveniles differentiate between representation of those who are guilty and not guilty is consistent with Grisso's (1981) findings. This is important because juveniles may interact with their lawyer differently based on whether they are guilty or not. Consistent with the findings of Redlich et al. (2003), juveniles do not always understand that they need to provide their lawyer with all relevant information about their case, even if it indicates their guilt. Future DVDs or teaching presentations of the court process should take special care to make sure juveniles understand that a lawyer's role does not differ based on whether or not they committed the crime.

Additionally, more than $75 \%$ of juveniles at both pre- and posttest answered that they should let the judge know if they do not understand what is happening in court. This meant that almost $20 \%$ of the juveniles in detention chose either "keep quiet and show the judge respect" (pretest $-4.2 \%$, posttest $-7.6 \%$ ) or "ask someone what the judge meant after the hearing" (pretest $-14.4 \%$, posttest $-11.0 \%$ ), which would leave them as passive members in the court process.

In examining social and demographic predictors of scores, age was found to be positively related to pretest scores, with older juveniles scoring higher. Race was also found to be significantly related to both pretest and improvement scores, with those identifying as White/Other scoring higher at pretest and those identifying as African American improving more. The variables of grades in school, gender, number of previous arrests, and 
number of previous times in court were evaluated but were not found to significantly predict either pretest or improvement scores.

Question content and format were found to impact scores. Participants performed the best on questions relating to the lawyer and attorney-client privilege. In the open-ended questions, the role of the lawyer and attorney-client privilege was also not one that juveniles had trouble with. Most indicated that their lawyer was the person they would tell information about their case if they wanted it to be kept just between the two of them, with most of those who answered indicating the reason was that the lawyer was the best person to help in that situation or worked for you. Our findings showed that most would disclose important facts about their case to their lawyer.

Peterson-Badali and Abramovitch (1992) and Saywitz (1989) noted that some of what children know about the legal system probably comes from television portrayals of courtrooms and the trial process; however, most of these portrayals are of the adult justice system and may be leading to some of the confusions the juveniles experience. We believe the media attention to the adult system may be one reason our juveniles seemed to understand the role of attorneys and the judge better than they understood the different hearings. The role of the defense attorney does not differ between juvenile and adult court, while the names of the hearings do differ. In addition, the names of the hearings were the longest (and arguably most difficult) words included in the DVD. Juveniles may have learned and understood what the purpose of different hearings were but had difficulty with the names of the specific hearings because they were longer and completely new terms for them (having not seen them in legal television shows). Future attempts to teach juveniles about the court process should include more information about the hearings. Likewise, attorneys and other court personnel should be aware that juveniles are having a difficult time with the juvenile court terminology for hearings.

A significant increase in mean pre- to posttest sure scores was found. Consistent with the Bradshaw et al. (2005) study concerning juror comfort and knowledge, posttest sureness was also found to be significantly related to improvement scores, with those who were more sure showing more improvement. This indicates that after watching the DVD juveniles felt surer of their answers and that those who improved more felt surer at posttest. In other words, juveniles seemed to be able to accurately assess their knowledge and knowledge improvement.

\section{Conclusion}

Overall, a short DVD does seem to help juveniles understand the court process; the only question is whether its effect can be further improved with slightly different implementation or additions. Future research should expand the scope of this study to include other sites throughout the state and randomly assign juveniles to settings where a question and answer period is permitted after watching the DVD, the person administering the DVD emphasizes the particularly difficult concepts (such as the hearing names), an active learning component is added, and the combination of these three conditions. Investigating these additional techniques will determine whether juvenile knowledge of the court system can be further enhanced using additional systematic techniques. 
Acknowledgments - The authors would like to thank Stacey Burweger, Candace Cabey, Drew Core, Ashley Croom, Jessica Custer, Tamika Edwards, Ashley Kolnes, Sarah Newton, Carlton Talbot, Chris West, Orli Zaprir, John Couch, P. K. Yonge Developmental Research School, the staff of the Alachua Regional Juvenile Detention Center, and the American Psychology-Law Society Grants-in-Aid. Portions of this research were presented at the 2006 American Psychology-Law Society Conference, St. Petersburg, Florida; the 2006 American Society of Criminology Annual Meeting, Los Angeles, California, and the 2008 American Psychology-Law Society Conference, Jacksonville, Florida. Contract/grant sponsor: American Psychology-Law Society.

\section{References}

Bonnie, R. (1992). The competence of criminal defendants: A theoretical reformulation. Behavioral Sciences and the Law, 10, 291-316.

Bradshaw, G. S., Ross, D. R., Bradshaw, E. E., Headrick, B., \& Thomas, W. N. (2005). Fostering juror comfort: Effects of an orientation videotape. Law and Human Behavior, 29, 457-467.

Chun, D. M., \& Plass, J. L. (1996). Effects of multimedia annotations on vocabulary acquisition. The Modern Language Journal, 80, 183-198.

Cooper, D. K. (1997). Juveniles' understanding of trial related information: Are they competent defendants? Behavioral Sciences and the Law, 15, 167-180.

Couch, J. K. (lead project staff). (2005). Tales from delinquency court [Short video]. (Available from the Office of Court Improvement for the State of Florida, Supreme Court Building, 500 South Duval Street, Tallahassee, FL 32399-1900, U.S.A.).

Duquette, L., \& Painchaud, G. (1996). A comparison of vocabulary acquisition in audio and video contexts. The Canadian Modern Language Review, 53, 143-172.

Dusky v. United States. 362 US 402 (1960).

Flin, R. H., Stevenson, Y., \& Davies, G. M. (1989). Children's knowledge of court proceedings. British Journal of Psychology, 80, 285-297.

Grisso, T. (1981). Juveniles' waiver of rights: Legal and psychological competence. New York: Plenum.

Incompetency in juvenile delinquency cases. 47 Fla. Stat. x 985.223 (2006).

Lotto, L., \& deGroot, A. M. B. (1998). Effects of learning method and word type on acquiring vocabulary in an unfamiliar language. Language Learning, 48, 31-69.

O'Connor, I. (1990). Can the children's court prevent further offending? Youth Studies, 9, 12-17.

O'Connor, I., \& Sweetapple, P. (1988). Children in Justice. Melbourne. Longman Cheshire.

Peterson-Badali, M., \& Abramovitch, R. (1992). Children's knowledge of the legal system: Are they competent to instruct legal counsel? Canadian Journal of Criminology, April,139-160.

Peterson-Badali, M., Abramovitch, R., \& Duda, J. (1997). Young children's legal knowledge and reasoning ability. Canadian Journal of Criminology, April, 145-170.

Redlich, A. D., Silverman, M., \& Steiner, H. (2003). Pre-adjudicative and adjudicative competence in juveniles and young adults. Behavioral Sciences and the Law, 21, 393-410.

Savitsky, J., \& Karras, D. (1984). Competency to stand trial among adolescents. Adolescence, 19, 349-358.

Saywitz, K. J. (1989). Children's conceptions of the legal system: “Court is a place to play basketball.” In S. J. Ceci, D. F. Ross, \& M. P. Toglia (Eds.), Perspectives on children's testimony (pp. 131-157). New York: Springer.

Saywitz, K., Jaenicke, C., \& Camparo, L. (1990). Children's knowledge of legal terminology. Law and Human Behavior, 14, 523-535. 
Smith, T. F. (1985). Law talk: Juveniles' understanding of legal language. Journal of Criminal Justice, 13, 339-353.

Use of detention. 47 Fla. Stat. x 985.213 (2006).

Warren-Leubecker, A., Tate, C. S., Hinton, I. D., \& Ozbek, I. N. (1989). What do children know about the legal system and when do they know it? First steps down a less traveled path in child witness research. In S. J. Ceci, D. F. Ross, \& M. P. Toglia (Eds.), Perspectives on children's testimony (pp. 158-183). New York: Springer. 